\title{
Roles of Individual Perception in Technology Adoption at Organization Level: Behavioral Model versus TOE Framework
}

\author{
Jerry C.F. Li \\ ADS Management Research \\ jerry.li@adssci.com
}

\begin{abstract}
It is generally accepted that two different groups of theories are required in order to explain technology adoption at individual level and at organization level. For individuals, behavioral theories including technology acceptance model (TAM), theory of planned behavior (TPB), unified theory of acceptance and use of technology (UTAUT) are frequently used to predict intention and actual behavior. For organizations, diffusion of innovation (DOI) model and technology-organization-environment (TOE) framework are commonly applied for predicting adoption. While this divide appears to be reasonable, the process of investigating an organization is, inevitably, done through collecting opinions of the people in the organization. This leads to the question how individual's perception affects the application of DOI and TOE for understanding organizational technology adoption. To extend further, what is an "objective" measure of organizational characteristics and who can provide it? In previous studies, researchers obtain feedback primarily only from decision makers when applying TOE. This paper examines if a decision-maker-centeredTOE analysis is consistent with the results obtained by directly applying behavior model to predict individual decision maker's action, and hence further justify TOE framework application. For this exploratory study, high degree of consistency is observed.
\end{abstract}

Keywords: Technology adoption, theory of reasoned action, theory of planned behavior, technology acceptance model, technology-organization-environment framework.

\section{Introduction}

Understanding why customers adopt a technological product or service is critical to the supplier. When target customers are individuals, behavioral models such as technology acceptance model (Davis, 1985; Davis, 1989; Davis and Venkatesh, 1996), theory of planned behavior (Ajzen, 1991), unified theory of acceptance and 
use of technology (Venkatesh, Morris, Davis \& Davis, 2003) are frequently used for analyzing the adoption decision (Koul \& Eydgahi, 2017). These models are rooted in psychological theories and hence suitable for investigating individual decision, but not directly applicable to organization decision (Ajzen \& Fishbein, 1977; Ajzen, 1991; Karahanna \& Straub, 1999). Thus, when target customers are organizations, the problem is analyzed by a different category of theory. Common theories for this scenario include diffusion of innovation (Rogers, 1962) and technologyorganization-environment framework (Tornatzky and Fleischer, 1990). In these theories, several organization characteristics have to be identified in order to predict technology adoption (Oliveira \& Martins, 2011; Hoti, 2015).

While using the two groups of theories to correspondingly analyze individual and organization adoption is a generally accepted practice, there is no serious study, as far as the author aware of, regarding how to fairly obtain the required organization characteristics when the target of analysis is an organization. Inevitably, these characteristics can only be obtained by surveying people in the organization. However, different members in the same organization may have very different assessments. For example, CEO of a company, head of IT, and a programmer may have completely different views on these organization characteristics when evaluating a software. These characteristics can be readiness to adopt, realizable advantages, competitive regime, etc. Surveying different people may produce significantly different predictions. Without a proven methodology to fairly determine these organization characteristics, most researchers choose to survey decision makers who have the power to approve final purchase (Oliveira \& Martins, 2010; Kuan \& Chau, 2001). This appears to be a reasonable approach, but also leads to a concern about the roles of individual perception in organization level theories. Afterall, the outcome of these theories will be dependent on the view of an individual (or a few individuals) on these organization characteristics. As such, the question is whether these organization level theories are fundamentally different from individual level theories, or they are simply alternative manifestations of individual level theories? Clarifying this issue is not only theoretically important, but also provides vital insights for practical research model design.

This paper explores the question by mapping selected results from a questionnaire-based survey into both behavioral model and TOE framework, and then compares their predictions. The survey was conducted last year, and results had been analyzed using a specific, individual level, behavioral model (Li, 2020). Out of 263 responses obtained, 117 are from decision makers. It has been demonstrated that the model can effectively predict organization adoption of blockchain technology when only responses from decision makers are taken into account. However, predictive power quickly deteriorates when other respondents are included. The observation suggests that, by carefully grouping and using the responses, individual level theories may also be applied for predicting organization 
level adoption. This study continues with the exploration by analyzing the same survey results under TOE framework and examines if the theory gives a complementary or competing explanation against the behavioral model.

This paper is organized as follow: In section 2, the relevant theories are briefly reviewed. Section 3 summarizes the analysis based on the behavioral model developed by Li (2020). Section 4 remaps the survey results into TOE framework and performs the necessary analyses for comparison. Finally, predictions from the two theories and implications are examined in Section 5.

\section{Relevant theories}

Relevant theories are briefly reviewed in this section.

\subsection{Predicting adoption by individual level theories}

Most individual level theories are behavioral models in nature. Starting from the theory of reasoned action (TRA), which is a generic model for predicting behavior, some important derived models had emerged. The theory of planned behavior (TPB) is a refined generic behavioral model evolved from TRA. Another model developed from TRA is technology acceptance model (TAM), which is, as its name has implied, a specialized model for predicting technology adoption. Unified theory of acceptance and use of technology (UTAUT) is a further enhancement of TAM. Each of these models also has some derivatives or refinements. Figure 1 depicts the relationships of the major models.

Developed by Ajzen and Fishbein (1977), TRA (Figure 1(a)) is the first theory systematically illustrated that an individual performing a particular behavior is not only influenced by his/her attitude towards that behavior, but also the subjective norm with respect to this behavior. Subjective norm refers to the individual's belief on how other relevant people think about him/her if he/she performs that behavior. With proper research design, TRA quantifies the influences of attitude and subjective norm, and explains many inconsistent behaviors observed in social science research (Ajzen and Fishbein, 1980).

Ajzen (1991) refined TRA by introducing an additional component known as perceived behavioral control (PBC), leading to the TPB model (Figure 1(b)). PCB refers to the individual's perception on how much control does he/she have to perform a certain behavior. There are two aspects of PBC (Ajzen, 2002; Ajzen and Madden, 1986): whether the individual perceives that he/she can access to the resources to perform the behavior, and whether he/she perceives there are opportunities to perform the behavior. A salient feature of PCB is its direct linkage to actual behavior: if the individual perceives that there is no opportunity to perform the behavior, he/she may actually not perform even though he/she has a positive behavioral intention to do so.

Both TRA and TPB are generic in nature and not specifically designed for particular situations. These theories have been extensively used to understand 
individual behavior in health-related issues, work-related issues, investment, product preference, eating habit, travelling and, of course, technology adoption. In order to apply these theories, researchers have to identify the appropriate variables for their study topics. In contrast, TAM (Figure 1(c)) uses two pre-determined constructs, perceived usefulness (PU) and perceived ease of use (PEOU), to predict adoption. The model shown is the original version of TAM, which was developed based on investigating adoption of word-processing software (Davis, 1985). In light of experiences gained from more applications, the inventor had revised the model a few times (Davis, 1989; Davis and Venkatesh, 1996). These revisions remain using PU and PEOU as the only two constructs for predicting adoption. Final version of TAM is shown in Figure 2 (Davis and Venkatesh, 1996). In addition, there are two expanded versions of TAM, namely TAM2 and TAM3, that include more constructs such as subjective norm, computer anxiety, etc. Details are provided in Venkatesh \& Davis (2000) and Venkatesh \& Bala (2008).

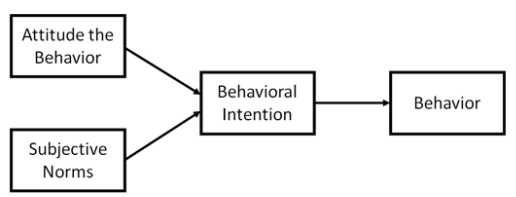

(a) Theory of Reasoned

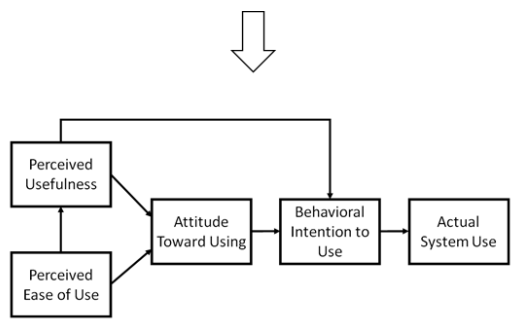

(c) Technology Acceptance Model

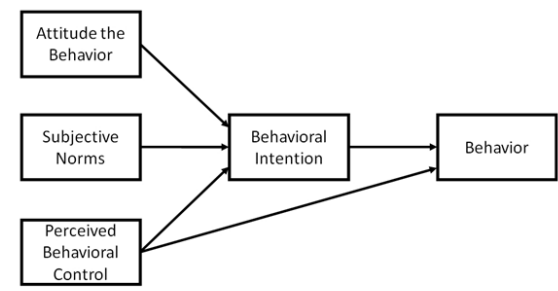

(b) Theory of Planned Behavior

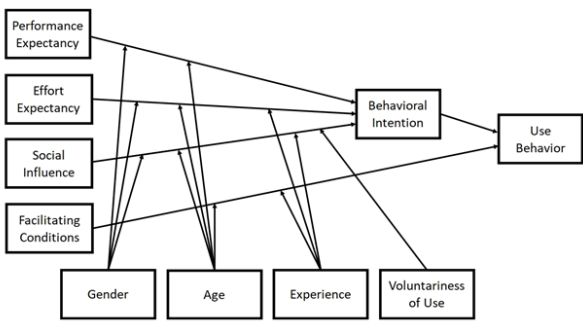

(d) Unified Theory of Acceptance and Use of Technology

Fig. 1: Individual level models.

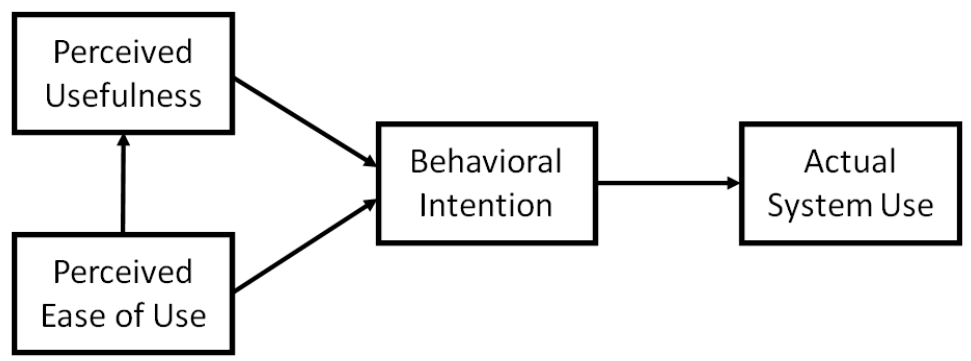

Fig. 2: Final version of technology acceptance model. 
While TAM is the most frequently used model for analyzing information technology adoption, the model has been frequently refined, expanded and modified since its deployment. This is not surprising because the model was originated from studying word-processing software acceptance in office environment in 1980s, which is relatively simple compared to the subsequent technology adoption problems down the timeline. Having examined TAM applications under different scenarios, researchers (Venkatesh \& Davis, 2000; Bagozzi, 2007; Venkatesh \& Bala, 2008) suggested that the model has left out important variables and processes for effective analysis for some cases. Another concern is appropriateness of the two constructs, PU and PEOU, under different applications. Researchers (Legris, Ingham \& Collerette, 2003; Ma \& Liu 2004; King \& He, 2006; Yousafzai, Foxall \& Pallister, 2007) conducted numerous meta-analyses covering TAM applications for various technologies, geographies, and participants. These studies indicated that PU remains as a significant predictor of behavioral intention in most cases, but the relative importance and significance of PEOU could be less concrete. This is consistent with Gefen and Straub's (2000) interpretation that PEOU is a dynamic construct and its influence is highly dependent on the nature of the problem under investigation, the technology, and the survey targets.

To address these difficulties, UTAUT (Figure 1(d)) is introduced as an enhancement (Venkatesh, Morris, Davis \& Davis, 2003). The model utilizes more generalized constructs and moderators to cater for wider range of applications, and explained about $70 \%$ of the variance in behavioral intention and $50 \%$ of the variance of actual usage in longitudinal field studies of employee technology acceptance. To further improve explanation of variance, an extended model, UTAUT2, had been proposed (Venkatesh, Thong \& Xu, 2012; 2016). Despite the apparent advantages, however, Bagozzi (2007) criticized the large number of variables used in UTAUT has led the study of technology adoption to a stage of chaos. van Raaij and Schepers (2008) challenged the grouping of many variables to represent a single psychometric construct, and pointed out that the high $\mathrm{R}^{2}$ is only achieved by excessive use of moderators. Li (2020) commented that conducting a lengthy survey with many variables is impractical under most real-life business settings.

\subsection{Predicting adoption by organization level theories}

Technology adoption in an organization is a two-folded problem. In one case, the research problem is to predict whether a company will purchase a certain technology. This is obviously a critical question for the supplier of that technology. In the other case, the company is aware about a technology and want to understand if most employees will adopt it over a period of time so as to consider purchasing. While these two problems are related, they are not the two sides of the same coin because the purchasing decision will not be made solely based on employee's acceptance of the technology. Other factors including the organization's business 
strategies, operation goals, vendor relationship, competitive environment, regulations, etc. must also be considered. It is worth pointing out that the second problem (i.e. employee adoption over a period of time) is essentially a collection of individual technology adoption problems under organizational constraints. For easy reference, the first problem (i.e. organization making purchase decision) is referred as Type I problem, and the second problem (i.e. employee adoption over a period of time) is referred as Type II problem.

Compared to individual level technology adoption, organizational level adoption is a less researched area. Two major models, diffusion on innovation (DOI, also known as innovation diffusion theory, IDT) model and technologyorganization-environment (TOE) framework, have been used for investigation. These models assume some specific characteristics of an organization are known or quite concretely determinable, and use them to infer technology adoption.

Originally a theory about social change, DOI model (Rogers, 1962) has a successful history of explaining social adoption of innovations. The theory examines adoption on a voluntary base, and describes the process as an information seeking and processing for an individual to reduce uncertainty about the advantages and disadvantages of an innovation (Figure 3). Furthermore, the theory outlines five attributes that promote adoption: (a) showing relative advantages over the existing approach; (b) compatible with existing values and practices; (c) simple and ease of use; (d) can be tried on a limited bias in order to reduce uncertainty; and (e) results are easily observable.

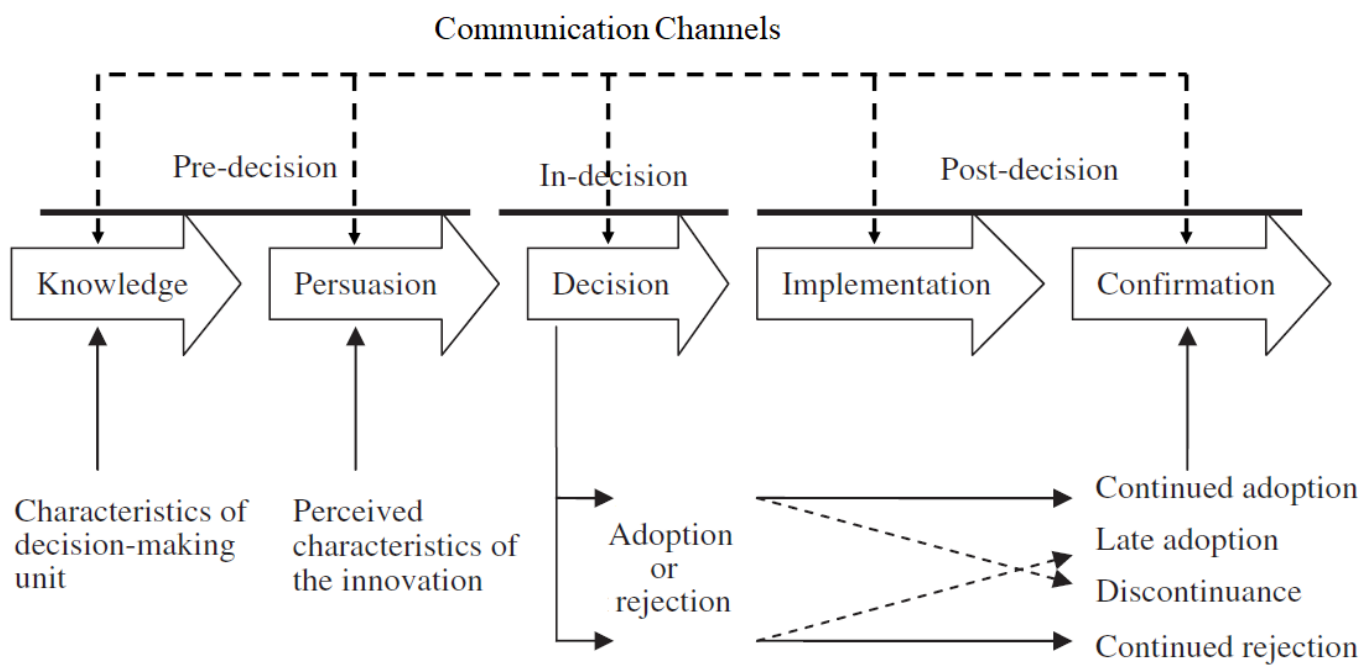

Fig. 3: Information seeking and processing in DOI model.

Unlike the behavioral models discussed in Section 2.1, this information seeking and processing exercise does not stop at the decision stage when an adopt or reject 
decision has been made. Instead, communication channels will drive the process to continue and decisions can change down the road. This indeed reflects the reality of changing individual technology acceptance decision in organization: some individual will adopt (or abandon) a technology faster than others, and the others may change their mind through the continuous information seeking and processing exercise. Thus, DOI model projects that the overall adoption in an organization will display a pattern as shown in Figure 4.

It should be clear that while both DOI model and the behavioral models in Section 2.1 are focusing on individual adoption, DOI model provides a continuous view on how technology adoption changes in an organization over a period. The behavioral models, on the other hand, are focusing on predicting individual decision at a specific timeslot. Thus, applying DOI model to Type II problem is more appropriate. However, DOI model is high level in nature and therefore researchers usually use the model in conjunction with TAM or other behavioral models in order to develop practically verifiable hypotheses for organization adoption (Dibra, 2015; Yu \& Tao, 2009; Zhou Y, 2008).

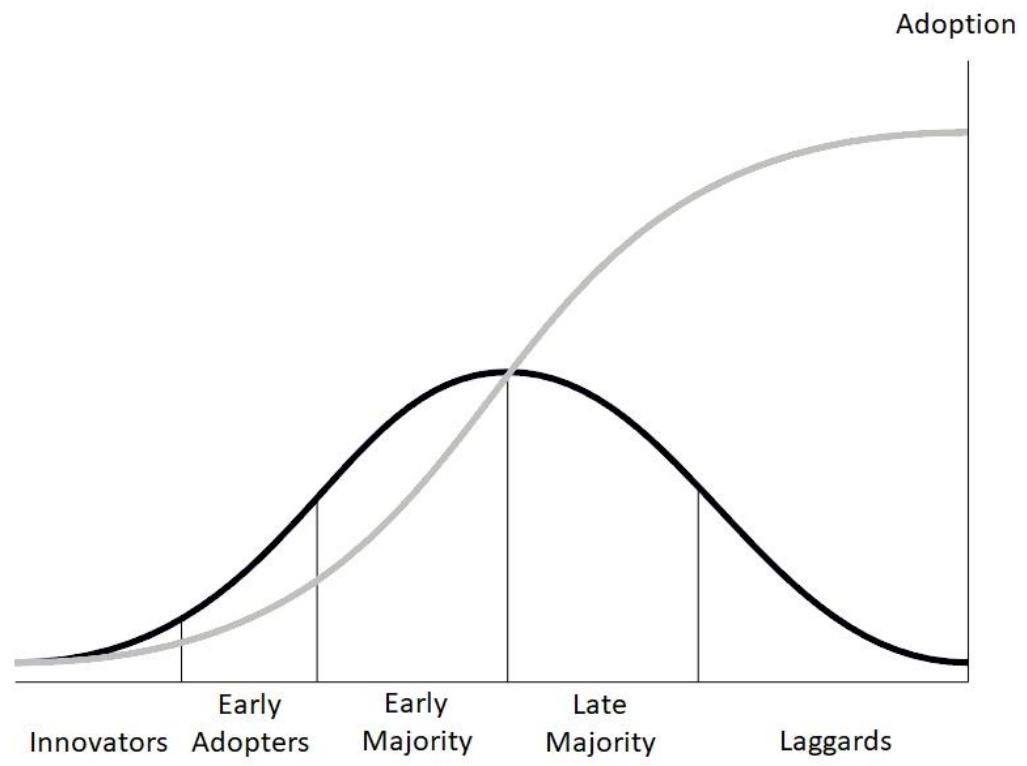

Fig. 4: Innovation adoption pattern in DOI.

TOE framework (Tornatzky \& Fleischer, 1990) responses to Type I problem by investigating organization technology adoption decision bases on organization characteristics. As the name of the framework implies, these characteristics are categorized as (a) technological; (b) organizational; and (c) environmental (Figure 5). 




Fig. 5: TOE framework.

While the framework appears to be straightforward, determining these characteristics could be challenging because they can only be understood by collecting opinions from the members of the organization. It is obvious that members of the same organization can have different, or even contradicting, views about these characteristics. Averaging the opinions would not be helpful because purchasing a technology (and hence adopting that technology from the organization's viewpoint) is usually not based on average opinion but the consent of a small group or even the opinion of a single decision maker. To avoid such ambiguity, most TOE-framework-based researches would only rely on input from decision makers (Awa, Ukoha \& Igwe, 2017; Yeh, Lee \& Pai, 2016; Hoti, 2015; Oliveira \& Martins, 2011; Oliveira \& Martins, 2010; Kuan \& Chau, 2001).

With this limitation, a question of choosing research model naturally arises: For Type I problem (i.e. organization purchasing a technology), is using TOE framework to predict an organization's decision practically equivalent to applying behavioral models to predict the behavior of the organization's decision maker? That is, will these two approaches lead to the same conclusion? As an exploratory analysis, this study developed a TRA model and a TOE model based on the same survey instrument and compared their predictions. The TRA model had been published in an earlier paper $(\mathrm{Li}, 2020)$ and the results are summarized in Section 3. Development and validation of the TOE model are illustrated in Section 4.

\section{TRA model for blockchain technology adoption: a summary}

A survey about blockchain technology adoption among small-to-medium size 
enterprises (SME) in Hong Kong was conducted from February to July of 2019. Anonymous questionnaires were distributed to audiences of a number of information technology seminars for SMEs. Surveys were administrated during the break. Numerous research studies (Gibson \& Bowling, 2020; Yan, Conrad, Tourangeau \& Couper, 2011; Galesic \& Bosnjak, 2009) had shown that length of questionnaire would adversely affect response rate and also induce careless responding. This is paticularly true in business environment. To ensure relevancy of responses, the questionnaire was brief and should take less then 10 minutes to answer.

Since this study intended to compare the outcome of behavioral model and TOE model, the questionnaire was designed to fit into both frameworks. Given the 10 minutes time constraint for answering the questionnaire, complex behavioral models such as TAM2, TAM3, UTAUT or UTAUT2 are impractical because too many variables and hence too many questions would be required. On the other hand, TAM, although simple, might not be a good choice because of the restriction of using only PU and PEOU as input constructs (Section 2.1). Considering simplicity as well as the flexibility to include additional constructs, TRA had been chosen as the behavioral model for this study.

The questionnaire designed for this research had only 23 questions: 3 brief background questions about the respondent (Table 1), and 20 research questions for model construction (Table 2).

Table 1: Background information

\begin{tabular}{l} 
Which of the followings best describe your business nature? \\
_ Manufacturing \\
_ Trading \\
_ Services \\
_ Retail \\
_ Others \\
\hline You company's annual revenue is: \\
_ Under USD 5M \\
- USD 5 - 25M \\
- USD 25-50M \\
_ Over USD 50M \\
Concerning about evaluating and /or investing in blockchain technologies, you \\
are: \\
- the final decision maker \\
- taking major responsibilities \\
- regularly involved \\
- occasionally involved \\
not involved
\end{tabular}


Table 2: Research questions for TRA model construction

\begin{tabular}{|c|c|c|c|}
\hline \multirow{2}{*}{ Item } & \multirow{2}{*}{ Description } & \multicolumn{2}{|c|}{ TRA } \\
\hline & & Construct & Variable \\
\hline 1 & $\begin{array}{l}\text { In our business, some process improvements } \\
\text { CANNOT be made without blockchain technologies. }\end{array}$ & \multirow{4}{*}{ PU } & PU_1 \\
\hline 2 & $\begin{array}{l}\text { Adopting blockchain technologies will enable our } \\
\text { company to offer new products / services that } \\
\text { CANNOT be provided in the past. }\end{array}$ & & PU_2 \\
\hline 3 & $\begin{array}{l}\text { Blockchain technologies can provide a justifiable } \\
\text { return on investment in a reasonable period of time. }\end{array}$ & & PU_3 \\
\hline 4 & $\begin{array}{l}\text { In our sector, companies who have implemented } \\
\text { blockchain technologies have gained competitive } \\
\text { advantages. }\end{array}$ & & PU_4 \\
\hline 5 & Blockchain technologies are safe and reliable. & \multirow{4}{*}{ PEOU } & PEOU_1 \\
\hline 6 & $\begin{array}{l}\text { For our business, there is no major operational barrier } \\
\text { for adopting blockchain technologies. }\end{array}$ & & PEOU_2 \\
\hline 7 & $\begin{array}{l}\text { Our employees can quickly cope with changes due to } \\
\text { deploying blockchain technologies. }\end{array}$ & & PEOU_3 \\
\hline 8 & $\begin{array}{l}\text { If needed, external implementation consultants are } \\
\text { readily available at a reasonable fee. }\end{array}$ & & PEOU_4 \\
\hline 9 & $\begin{array}{l}\text { At a regional / country level, authorities are } \\
\text { encouraging companies to adopt blockchain } \\
\text { technologies. }\end{array}$ & \multirow{3}{*}{ PTRD } & PTRD_1 \\
\hline 10 & $\begin{array}{l}\text { Adopting blockchain technologies is becoming a trend } \\
\text { in many business sectors. }\end{array}$ & & PTRD_2 \\
\hline 11 & $\begin{array}{l}\text { More companies in OUR sector will adopt blockchain } \\
\text { technologies in the NEAR future. }\end{array}$ & & PTRD_3 \\
\hline 12 & $\begin{array}{l}\text { Our customers would expect our company to use } \\
\text { blockchain technologies. }\end{array}$ & \multirow{3}{*}{ NOR } & NOR_1 \\
\hline 13 & $\begin{array}{l}\text { Our suppliers would expect our company to use } \\
\text { blockchain technologies. }\end{array}$ & & NOR_2 \\
\hline 14 & $\begin{array}{l}\text { Our employees would expect our company to use } \\
\text { blockchain technologies. }\end{array}$ & & NOR_3 \\
\hline 15 & Blockchain technologies can improve our operation & \multirow[b]{2}{*}{ ATT } & ATT_1 \\
\hline 16 & $\begin{array}{l}\text { In an overall sense, blockchain technologies are good } \\
\text { for our company. }\end{array}$ & & ATT_2 \\
\hline 17 & $\begin{array}{l}\text { I believe our company should implement blockchain } \\
\text { technologies in NEAR future. }\end{array}$ & \multirow[b]{2}{*}{ BI } & BI_1 \\
\hline 18 & $\begin{array}{l}\text { I am actively cultivating agreement among other } \\
\text { relevant members in the company to adopt blockchain } \\
\text { technologies. }\end{array}$ & & BI_2 \\
\hline 19 & $\begin{array}{l}\text { We are working out / already have an implementing } \\
\text { plan with budget for blockchain technologies. }\end{array}$ & \multirow{2}{*}{ B } & B_1 \\
\hline 20 & $\begin{array}{l}\text { We have spent / scheduled to spend remarkably on } \\
\text { implementing blockchain technologies. }\end{array}$ & & B_2 \\
\hline
\end{tabular}


By the end of the survey period, 263 valid responses had been collected. For the purpose of this study, only responses from "final decision makers" and those who claimed to be "taking major responsibilities" (Table 3.1) for technology adoption in their organizations were used for model construction. In the context of this research, these respondents were collectively referred as decision makers. Additionally, since big companies and small companies could have very different resources for technology deployment, responses from companies with annual revenue less than USD 5M or more than USD 50M were excluded (Table 3.1). Under these criteria, 117 responses were considered as vital responses from decision makers. After standard validation and statistical analysis, a TRA model based on these 117 responses was obtained (Figure 6, referred as Model 1). While most hypotheses in the proposed model (Li, 2020) were supported, it is interesting to note that PEOU is not a significant predictor of attitude to adopt (ATT). As discussed in Section 2.1, the same phenomenon had been observed in many previous meta-analyses on TAM applications (Legris, Ingham \& Collerette, 2003; Ma \& Liu 2004; King \& He, 2006; Yousafzai, Foxall \& Pallister, 2007). In this study, the observation could possibly be accounted by the fact that decision makers may not be the one who actual use the technology so they may not consider, or even not aware, ease of use as a crucial factor. Alternatively, other factors such as market trend, financial return, etc. could be far more important in the mind of decision makers so PEOU had insignificant effect in the model.

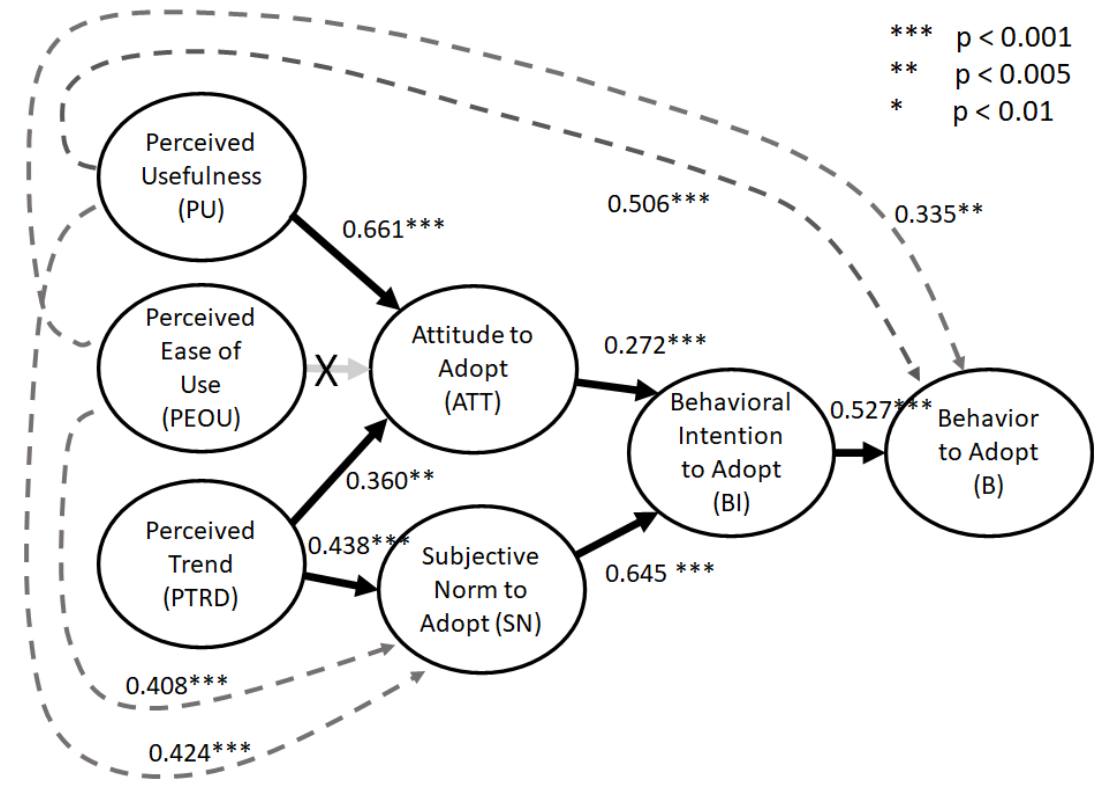

Fig. 6: TRA model based solely on responses from decision makers (Model 1)

As exploratory analyses, two additional trial models utilizing responses from 
more respondents were computed. In model 2, answers from respondents who claimed to be "regularly involved" (Table 3.1) in technology adoption had been included. In model 3, all responses had been included. Predictive power of the three models were compared (Table 3). Details are provided in Li (2020).

Table 3: Indicative predictive power comparison

\begin{tabular}{|c|ccc|}
\hline \multirow{2}{*}{$\mathbf{R}^{2}$} & $\begin{array}{c}\text { Model 1 } \\
(\mathbf{N = 1 1 7})\end{array}$ & $\begin{array}{c}\text { Model 2 } \\
(\mathbf{N = 1 5 9})\end{array}$ & $\begin{array}{c}\text { Model 3 } \\
\mathbf{( N = 2 6 3 )}\end{array}$ \\
\cline { 2 - 4 } & $\begin{array}{c}\text { Decision } \\
\text { makers } \\
\text { only }\end{array}$ & $\begin{array}{c}\text { Decision makers and } \\
\text { those with regular } \\
\text { involvement }\end{array}$ & All respondents \\
\hline Behavior to adopt (B) & $70.2 \%$ & $29.3 \%$ & $18.2 \%$ \\
\hline Behavioral intention to adopt (BI) & $72.6 \%$ & $73.0 \%$ & $65.3 \%$ \\
\hline
\end{tabular}

While all three models can reasonably predict behavioral intention (BI), only Model 1 can meaningfully predict actual adopt (B). Since responses were collected during IT seminars, most participants would have good IT literacy and therefore high R2 for BI should not be surprising. For implementation, however, R2 for B dropped very remarkably when responses from non-decision-makers were included. This could be an indication that behavioral intentions of most non-decision-makers could not be translated into actual adoption (or rejection) due to lack of power to make actual decision.

\section{TOE model for blockchain technology adoption}

The current scenario of housing affordability situation of middle-income group in Son The questionnaire in Section 3 was designed to fit into both TRA model and TOE model. In this section, the questionnaire is remapped into TOE categories, followed by a preliminary data analysis. A TOE model is then proposed and validated.

To remap the questionnaire, five TOE categories are defined. These five constructs are:

(a) Technical advantage (TADV) - this construct accounts for, from technical perspectives, process improvement, new product offering, cost reduction, enhanced reliability, and other advantages that the concerned technology may lead to;

(b) Organization readiness (ORDY) - this construct examines if the organization is ready to adopt the technology base on operation, human resources, and other supporting requirements;

(c) Management support (OMSP) - this construct measures the management's willingness to adopt the technology via general impression, investment justification, actions taken, etc.

(d) General trend (EGEN) - this construct represents the broad impression about the development direction of the technology under examination; 
(e) Stakeholder (ESTK) - this construct concerns about stakeholder expectations.

In addition, the construct IMPN measures the implementation of adoption (or rejection) plan. Remapped research questions are listed in Table 4.

Table 4: Research questions for TOE model construction

\begin{tabular}{|c|c|c|c|}
\hline \multirow{2}{*}{ Item } & \multirow{2}{*}{ Description } & \multicolumn{2}{|c|}{ TOE } \\
\hline & & Construct & Variable \\
\hline 1 & $\begin{array}{l}\text { In our business, some process improvements CANNOT be } \\
\text { made without blockchain technologies. }\end{array}$ & \multirow{5}{*}{ TADV } & TADV_1 \\
\hline 2 & $\begin{array}{l}\text { Adopting blockchain technologies will enable our company to } \\
\text { offer new products / services that CANNOT be provided in the } \\
\text { past. }\end{array}$ & & TADV_2 \\
\hline 4 & $\begin{array}{l}\text { In our sector, companies who have implemented blockchain } \\
\text { technologies have gained competitive advantages. }\end{array}$ & & TADV_3 \\
\hline 5 & Blockchain technologies are safe and reliable. & & TADV_4 \\
\hline 15 & Blockchain technologies can improve our operation & & TADV_5 \\
\hline 6 & $\begin{array}{l}\text { For our business, there is no major operational barrier for } \\
\text { adopting blockchain technologies. }\end{array}$ & \multirow{3}{*}{ ORDY } & ORDY_1 \\
\hline 7 & $\begin{array}{l}\text { Our employees can quickly cope with changes due to } \\
\text { deploying blockchain technologies. }\end{array}$ & & ORDY_2 \\
\hline 8 & $\begin{array}{l}\text { If needed, external implementation consultants are readily } \\
\text { available at a reasonable fee. }\end{array}$ & & ORDY_3 \\
\hline 3 & $\begin{array}{l}\text { Blockchain technologies can provide a justifiable return on } \\
\text { investment in a reasonable period of time. }\end{array}$ & \multirow{4}{*}{ OMSP } & OMSP_1 \\
\hline 16 & $\begin{array}{l}\text { In an overall sense, blockchain technologies are good for our } \\
\text { company. }\end{array}$ & & OMSP_2 \\
\hline 17 & $\begin{array}{l}\text { I believe our company should implement blockchain } \\
\text { technologies in NEAR future. }\end{array}$ & & OMSP_3 \\
\hline 18 & $\begin{array}{l}\text { I am actively cultivating agreement among other relevant } \\
\text { members in the company to adopt blockchain technologies. }\end{array}$ & & OMSP_4 \\
\hline 9 & $\begin{array}{l}\text { At a regional / country level, authorities are encouraging } \\
\text { companies to adopt blockchain technologies. }\end{array}$ & \multirow{3}{*}{ EGEN } & EGEN_1 \\
\hline 10 & $\begin{array}{l}\text { Adopting blockchain technologies is becoming a trend in many } \\
\text { business sectors. }\end{array}$ & & EGEN_2 \\
\hline 11 & $\begin{array}{l}\text { More companies in OUR sector will adopt blockchain } \\
\text { technologies in the NEAR future. }\end{array}$ & & EGEN_3 \\
\hline 12 & $\begin{array}{l}\text { Our customers would expect our company to use blockchain } \\
\text { technologies. }\end{array}$ & \multirow{3}{*}{ ESTK } & ESTK_1 \\
\hline 13 & $\begin{array}{l}\text { Our suppliers would expect our company to use blockchain } \\
\text { technologies. }\end{array}$ & & ESTK_2 \\
\hline 14 & $\begin{array}{l}\text { Our employees would expect our company to use blockchain } \\
\text { technologies. }\end{array}$ & & ESTK_3 \\
\hline 19 & $\begin{array}{l}\text { We are working out / already have an implementing plan with } \\
\text { budget for blockchain technologies. }\end{array}$ & \multirow{2}{*}{ IMPN } & IMPN_1 \\
\hline 20 & $\begin{array}{l}\text { We have spent / scheduled to spend remarkably on } \\
\text { implementing blockchain technologies. }\end{array}$ & & IMPN_2 \\
\hline
\end{tabular}


Based on the 117 responses from decision makers, Cronbach's alpha test (Table 5) and discriminant validity test (Table 6) are performed.

Table 5: Cronbach's alpha test

\begin{tabular}{|c|c|c|c|}
\hline & No. of variables & No. of data & Cronbach's alpha \\
\hline TADV & 5 & 117 & 0.83 \\
\hline ORDY & 3 & 117 & 0.76 \\
\hline OMSP & 4 & 117 & 0.90 \\
\hline EGEN & 3 & 117 & 0.71 \\
\hline ESTK & 3 & 117 & 0.89 \\
\hline IMPN & 2 & 117 & 0.92 \\
\hline
\end{tabular}

Cronbach's alpha greater than 0.7 indicates satisfactory internal reliability (Nunnaly, 1978). Thus, numerical average of the variables in a category can properly represent their corresponding construct.

Table 6: Discriminant Validity

\begin{tabular}{|l|ccc|}
\hline & $\begin{array}{c}\text { Correlation } \\
\text { coefficient (r) }\end{array}$ & $\begin{array}{c}\text { Standard Error } \\
\text { (SE) }\end{array}$ & 1 - r - 2*SE \\
\hline TADV - ORDY & 0.41 & 0.08 & 0.44 \\
TADV - OMSP & 0.85 & 0.04 & 0.08 \\
TADV - EGEN & 0.77 & 0.07 & 0.10 \\
TADV - ESTK & 0.75 & 0.05 & 0.16 \\
TADV - IMPN & 0.75 & 0.04 & 0.17 \\
\hline ORDY - OMSP & 0.64 & 0.06 & 0.24 \\
ORDY - EGEN & 0.48 & 0.10 & 0.32 \\
ORDY - ESTK & 0.61 & 0.06 & 0.26 \\
ORDY - IMPN & 0.63 & 0.05 & 0.27 \\
\hline OMSP - EGEN & 0.72 & 0.10 & 0.08 \\
OMSP - ESTK & 0.89 & 0.05 & 0.02 \\
OMSP - IMPN & 0.84 & 0.05 & 0.07 \\
\hline EGEN - ESTK & 0.75 & 0.04 & 0.17 \\
EGEN - IMPN & 0.55 & 0.05 & 0.36 \\
\hline ESTK - IMPN & 0.77 & 0.05 & 0.13 \\
\hline
\end{tabular}

According to Bagozzi and Warshaw (1980), discriminant validity can be claimed if

$$
1-\mathrm{r}-\mathrm{SE}>0
$$

where $\quad r$ is the correlation coefficient. SE is the standard error 


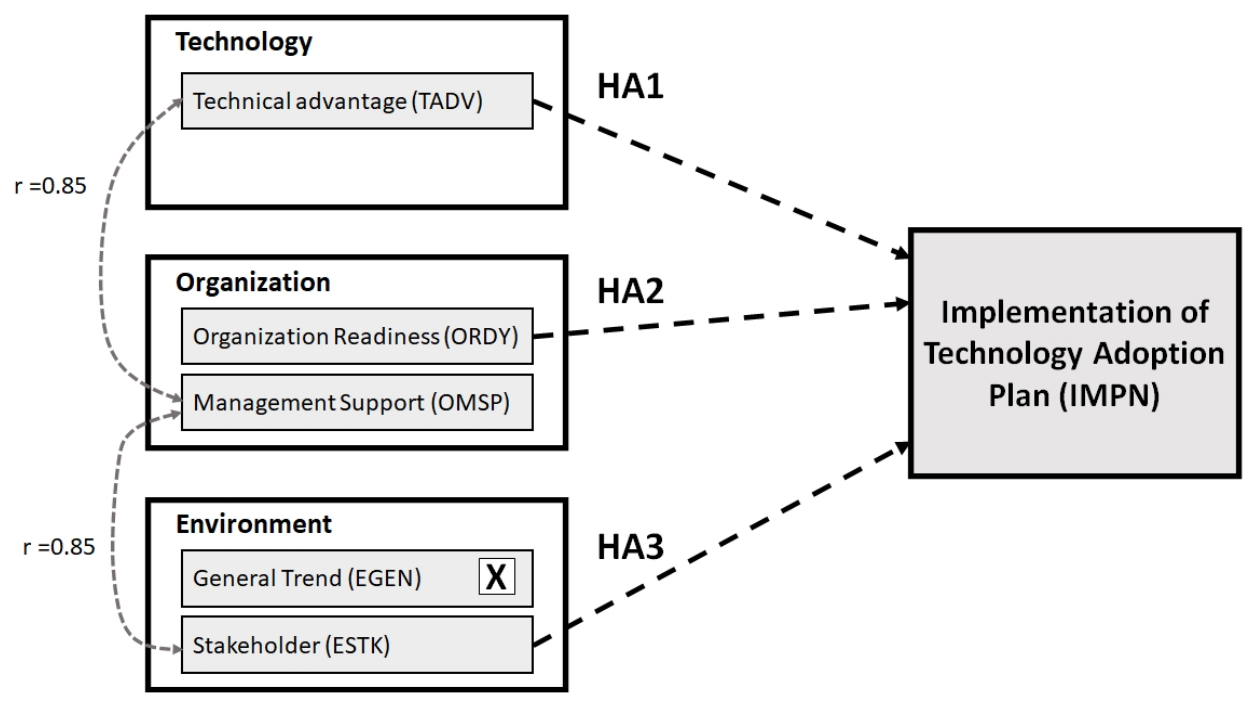

(a) TOE Model A

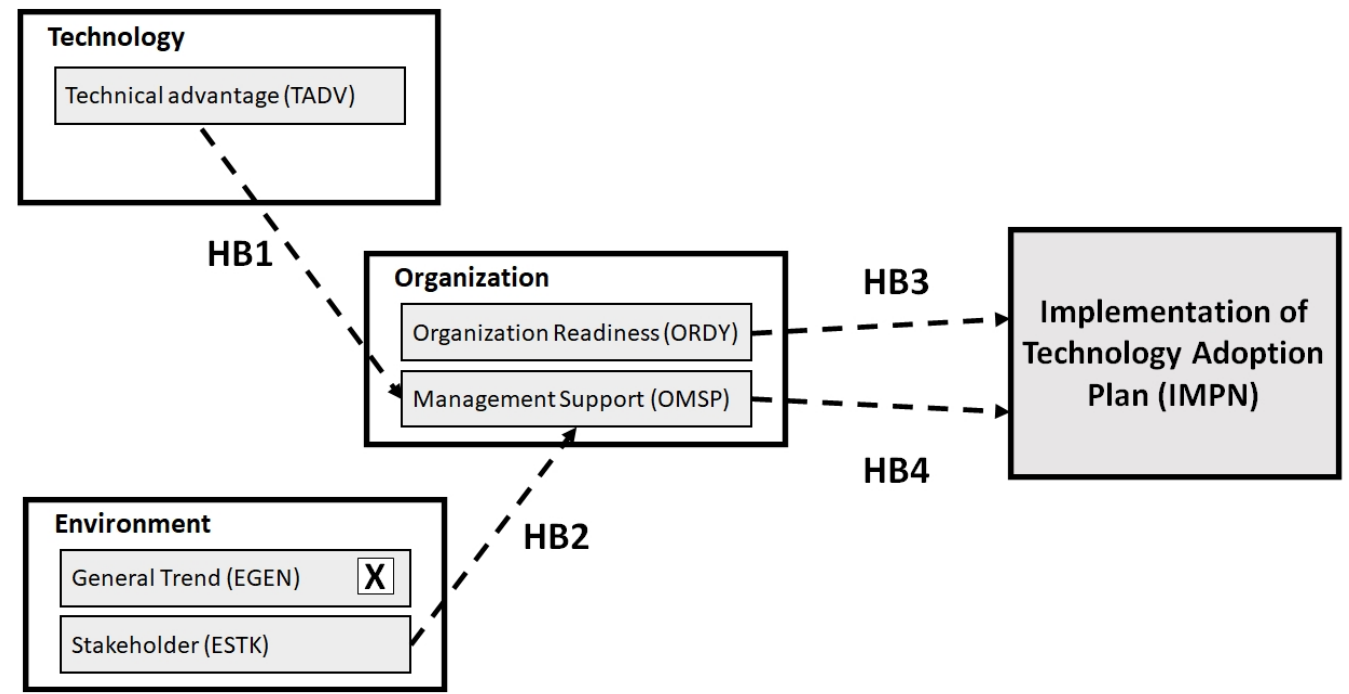

(b) TOE Model B

Fig. 7: Proposed TOE models based solely on responses from decision makers.

Thus, as shown in Table 4.3, discriminant validity is also satisfied.

To develop a vital TOE model, correlations among the variables are examined. Three important observations are: (i) correlation between input variables OMSP and ESTK is very high; (ii) correlation between input variables TADV and OMSP is very high; and (iii) correlation between input variable EGEN and output variable 
IMPN is low.

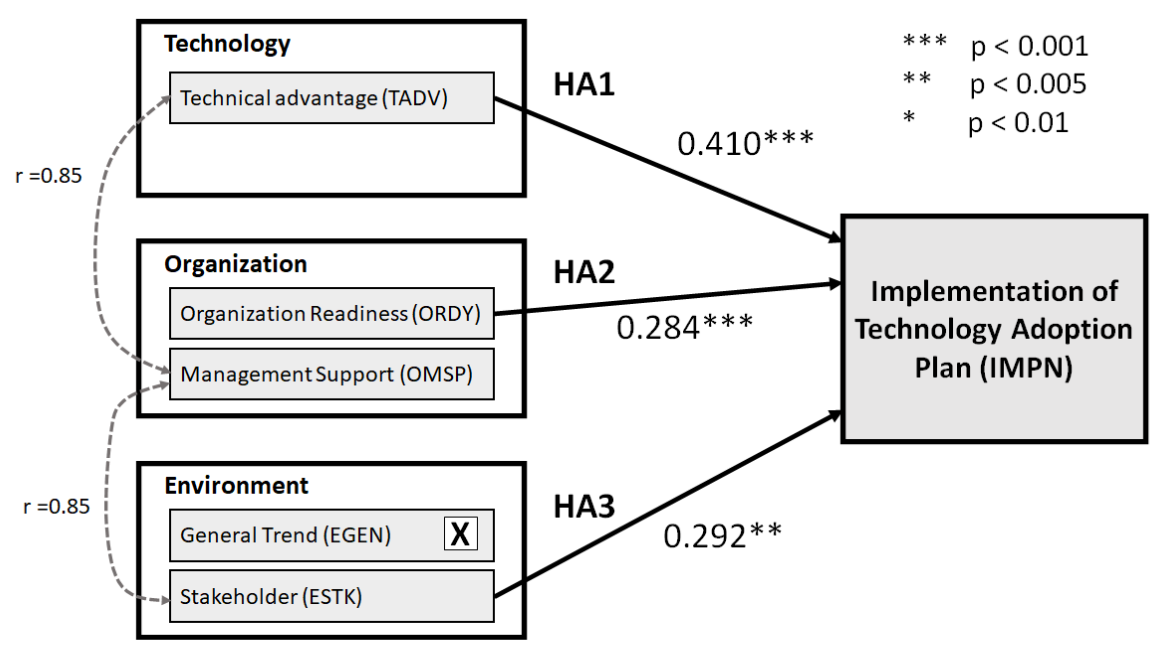

(a) TOE Model A

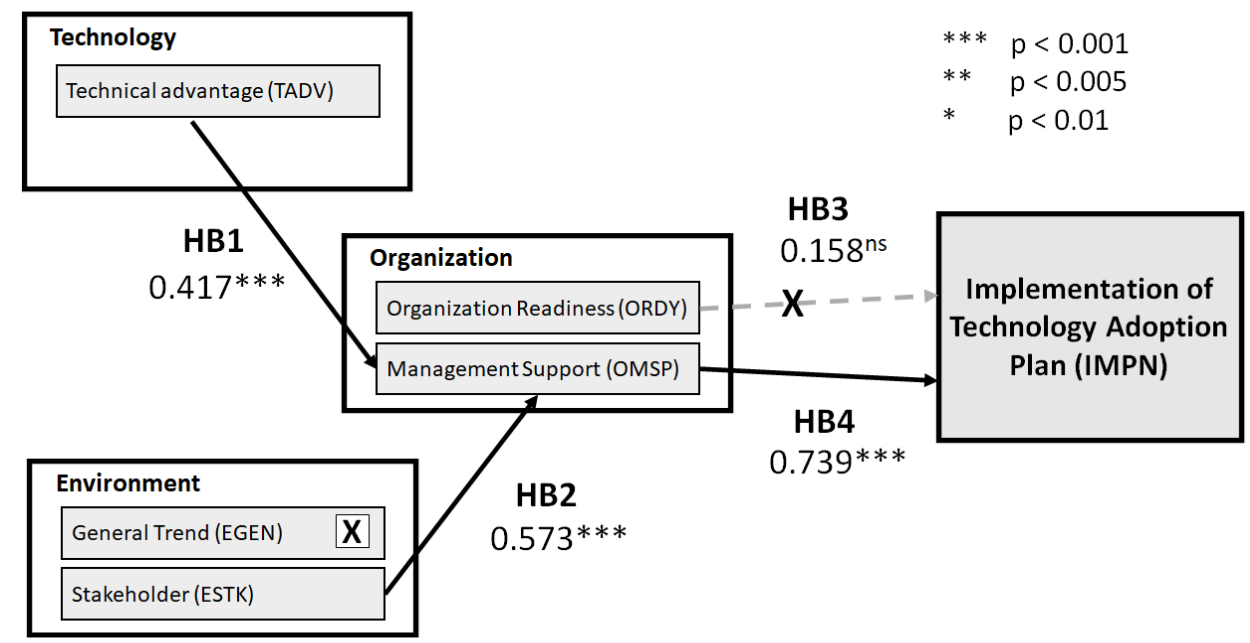

(b) TOE Model B

Fig. 8: Validated TOE model based solely on responses from decision makers.

Because of its low relevance, EGEN is excluded in order not to unnecessarily increase standard error. To avoid potential multicollinearity problem, there are some possible choices. For example:

(a) Omit OMSP and link both TADV and ESTK to IMPN; or

(b) Put OMSP as a mediating variable that links TADV and ESTK to IMPN.

Two models are proposed accordingly, with all hypotheses (HA1-3, HB1-4) 
postulating positive correlations between concerned variables (Figure 7).

Multiple regression is used to analyze the hypotheses. Results are summaries in Figure 8.

While all hypotheses in Model A are supported, HB3 (i.e. effect of ORDY) in Model B is not. The apparent inconsistency suggests that effect of ORDY may mediate through OMSP. A mediation test (Baron and Kenny, 1986; Judd and Kenny, 1981) has verified this assumption (Table 7).

Table 7: Mediation test (non-significant when $\mathrm{p}>0.01$ )

\begin{tabular}{|c|c|c|c|}
\hline Constructs & Correlation Coefficient & p-value & Mediation \\
\hline ORDY - IMPN & 0.633 & 0.000 & \multirow{2}{*}{ Full } \\
\hline ORDY - OMSP & 0.642 & 0.000 & \multirow{2}{*}{} \\
\hline $\begin{array}{c}\text { ORDY - IMPN } \\
\text { OMSP }\end{array}$ & 0.158 & 0.015 & \\
\cline { 2 - 3 }
\end{tabular}

Accordingly, Model B has been modified to reflect the mediation relation. The resulting model (Model C, Figure 9) has been satisfactorily validated.

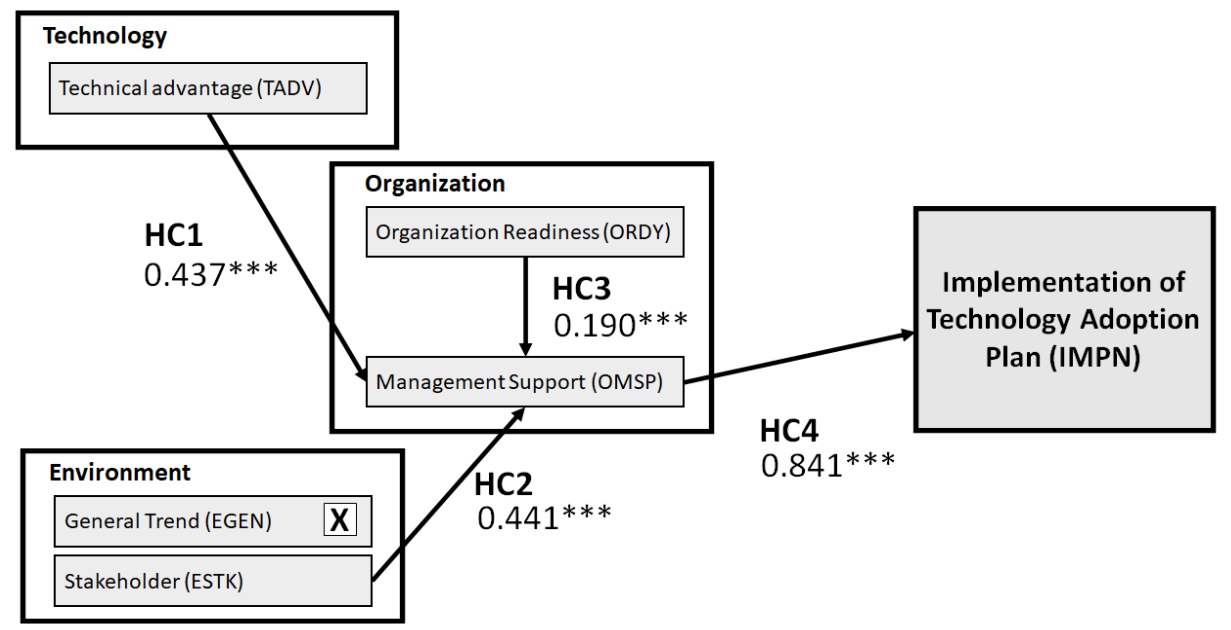

Fig. 9: Validated TOE Model C.

Thus, two vital models, Model A and Model C, are obtained base on the TOE framework.

\section{Discussions and Conclusion}

Model C resembles, to a good degree, Model 1 in Figure 6 after slight rearrangement (Figure 9). Comparing the two models, TADV's role is similar to PU, ORDY to PEOU, and ESTK to SN. Other mediating variables in Model 1 are replaced by OMSP in Model C. R2 of Model 1 is $70.2 \%$ and that of Model C is 
$71.1 \%$.

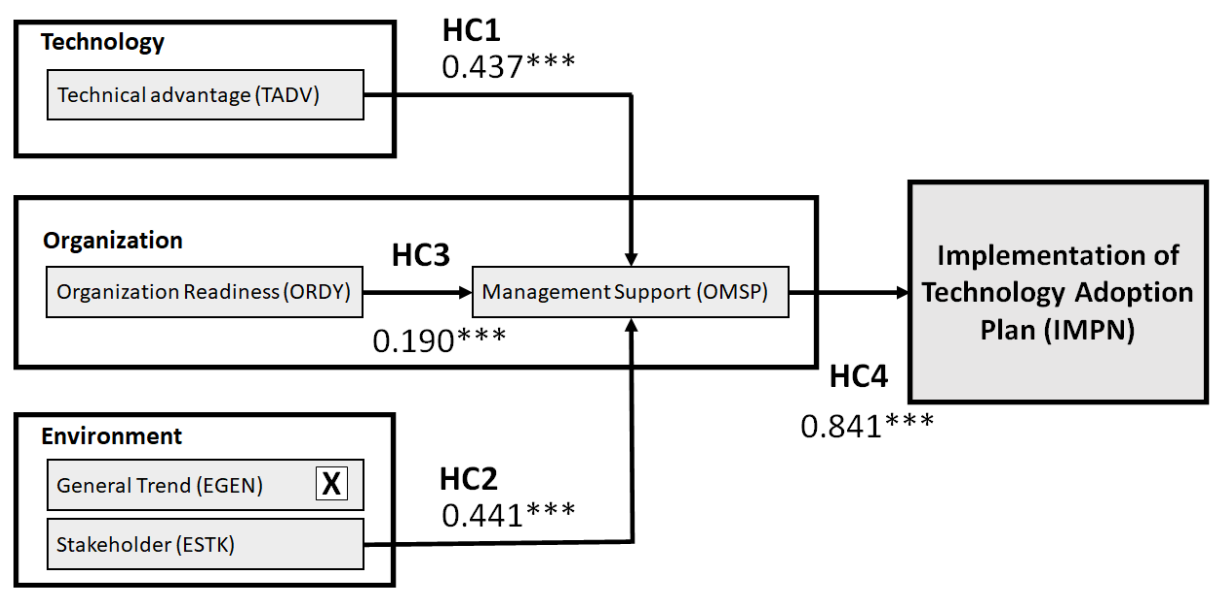

Fig. 10: Model C rearranged.

It should be realized that Model 1 is a behavioral model predicting decision maker's technology adoption action, and Model $\mathrm{C}$ is a technology adoption model built on organization characteristics obtained from decision makers. As such, they started from different theoretical bases, and this is an important rationale for most literatures to classify behavioral model and TOE framework as, respectively, individual level theory and organization level theory. However, the resemblance shown in this study suggests the models can offer similar explanation of the adoption action and would practically lead to similar results.

Thus, besides deriving classical TOE model such as Model A, the TOE framework can also generate models compatible to behavioral-theoretic, and hence endorses its applicability. Baker (2012) has remarked that TOE framework is lacking of development because the theory is too generic and offers complementary, instead of competing, explanation to other organization level theories such as DOI. As such, there is no need for theorists to modify the framework. This is probably true from the viewpoint of developing the theory itself. Compared to TAM and other behavioral models, there are in fact much less TOE literatures in both theory and application. For practitioners, however, TOE framework is easy to use in reallife business settings but more justifications are necessary. As an exploratory attempt, this study has examined the equivalence of TOE framework and the well proven behavioral models under the situation where only decision makers' views are considered. The results add to justifications for applying TOE framework in practical business environment.

Regarding limitations, it is obvious that the research was only based on adoption of one specific technology among SMEs in a city. Most survey 
respondents have relatively high level of IT proficiency, which might make their responses different from a wider range of general IT users. Thus, the findings in this study cannot be over-generalized and further researches covering different range of participants for other products/services and geographies are essential.

\section{References}

Ajzen I. (1991). The theory of planned behaviour. Organizational Behavior and Human Decision Processes, 50, 179-211.

Ajzen I. (2002). Perceived behavioral control, self-efficacy, locus of control, and the theory of planned behavior. Journal of Applied Social Psychology, 32, 665-683.

Ajzen I and Fishbein M. (1977). Attitude-behavior relations: A theoretical analysis and review of empirical research. Psychological Bulletin, 85(5), 888-918.

Ajzen I and Fishbein M. (1980). Understanding attitudes and predicting social behaviour. Prentice-Hall, Inc.

Ajzen I and Madden T. (1986). Prediction of goal directed behavior: Attitudes, intentions, and perceived behavioral control. Journal of Experimental Social Psychology, 22, 453-474.

Awa H, Ukoha O \& Igwe S. (2017). Integrated technology-organizationenvironment (T-O-E) taxonomies for technology adoption. Journal of Enterprise Information Management, 30(6), 893-921.

Bagozzi R and Warshaw P. (1980). Trying to Consume. Journal of Consumer Research, 17,127-140.

Bagozzi R. (2007). The legacy of the technology acceptance model and a proposal for a paradigm shift. Journal of the Association for Information Systems, 8(4), 244 254.

Baker J. (2012). The Technology-Organization-Environment Framework, section 12.3.1. Information Systems Theory: Explaining and Predicting Our Digital Society, Editor: Dwivedi Y, et. al., Springer, 237-241.

Baron R and Kenny D. (1986). The moderator-mediator variable distinction in social psychological research: Conceptual, strategic, and statistical considerations. Journal of Personality and Social Psychology, 51, 1173-1182. 
Davis F. (1985). A technology acceptance model for empirically testing new enduser information systems: theory and results. doctoral dissertation, MIT Sloan School of Management, Cambridge, MA.

Davis F. (1989). Perceived usefulness, perceived ease of use, and user acceptance of information technology. Management Information Systems (MIS) Quarterly, 13(3), 319-340.

Davis F and Venkatesh V. (1996). A critical assessment of potential measurement biases in the technology acceptance model: three experiments. International Journal of Human-Computer Studies, 45(1), 19-45.

Dibra M. (2015). Rogers Theory on Diffusion of Innovation - the most appropriate theoretical model in the study of factors influencing the integration of sustainability in tourism businesses. Procedia - Social and Behavioral Sciences, 195, 1453-1462.

Galesic M and Bosnjak M. (2009). Effects of Questionnaire Length on Participation and Indicators of Response Quality in a Web Survey. Public Opinion Quarterly, 73(2), 349-360.

Gefen D and Straub D. (2000). The Relative Importance of Perceived Ease of Use in IS Adoption: A Study of E-Commerce Adoption. Journal of the Association for Information Systems, 1(1), Article 8.

Gibson A and Bowling N. (2020). The Effects of Questionnaire Length and Behavioral Consequences on Careless Responding. European Journal of Psychological Assessment, 36(2), 410-420.

Hoti E. (2015). The technological, organizational and environmental framework of IS innovation adoption in small and medium enterprises: evidence from research over the last 10 years. International Journal of Business and Management, III(4), 114.

Judd C and Kenny D. (1981). Process analysis: Estimating mediation in treatment evaluations. Evaluation Review, 5, 602-619.

Karahanna E and Straub D. (1999). The psychological origins of perceived usefulness and ease-of-use. Information and Management, 35, 237-250.

King W and He L. (2006). A meta-analysis of the technology acceptance model. Information and Management, 43(6), 740-755. 
Koul S and Eydgahi A. (2017). A systematic review of technology adoption frameworks and their applications. Journal of Technology Management \& Innovation, 12(4), 106-112.

Kuan K and Chau P. (2001). A perception-based model for EDI adoption in small businesses using a technology-organization-environment framework. Information and Management, 38, 507-521.

Legris P, Ingham J \& Larsen K. (2003). Why do People Use Information Technology? A Critical Review of the Technology Acceptance Model. Information and Management, 40, 191-204.

Li J. (2020). Blockchain Technology Adoption: Examining the Fundamental Drivers", Proceedings of the 2020 2nd International Conference on Management Science and Industrial Engineering, ACM Publication, 253-260.

Ma Q and Liu L. (2004). The technology acceptance model: a meta-analysis of empirical findings. Journal of Organizational and End User Computing, 16(1), 5972.

Nunnaly, J. (1978). Psychometric Theory. New York: McGraw Hill.

Oliveira T and Martins M. (2010). Understanding e-business adoption across industries in European countries. Industrial Management and Data Systems, 110(9), 1337-11354.

Oliveira T and Martins M. (2011). Literature Review of Information Technology Adoption Models at Firm Level. The Electronic Journal Information Systems Evaluation, 14(1), 110-121.

Rogers E. (1962). Diffusion of innovations. 1st Ed., Free Press of Glencoe, New York.

Tornatzky L and Fleischer M. (1990). The processes of technological innovation. Lexington, $M A$.

van Raaij E and Schepers J. (2008). The acceptance and use of a virtual learning environment in China.Computers \& Education, 50(3), 838-852.

Venkatesh V and Bala H. (2008). Technology Acceptance Model 3 and a Research Agenda on Interventions. Decision Sciences, 39(2), 273-315. 
Venkatesh V and Davis F. (2000). A Theoretical Extension of the Technology Acceptance Model: Four Longitudinal Field Studies. Management Science, 46(2), 186-204.

Venkatesh V, Morris M, Davis G \& Davis F. (2003). User Acceptance of Information Technology: Toward a Unified View. Management Information Systems (MIS) Quarterly, 27(3), 425-478.

Venkatesh V, Thong J \& Xu X. (2012). Consumer acceptance and use of information technology: Extending the unified theory of acceptance and use of technology. Management Information Systems (MIS) Quarterly, 36(1), 157-178.

Venkatesh V, Thong J \& Xu X. (2016). Unified theory of acceptance and use of technology: a synthesis and the road ahead. Journal of the Association for Information Systems, 17(5), 328-376.

Yeh C, Lee G \& Pai J. (2016). Using a technology-organization-environment framework to investigate the factors influencing e-business information technology capabilities. Information Development, 31(5), 435-450.

Yousafzai S, Foxall G, and Pallister J. (2007). Technology acceptance: a metaanalysis of the TAM: Part 1", Journal of Modelling in Management, 2(3), 252-280.

Yan T, Conrad F, Tourangeau R \& Couper M. (2011). Should I Stay or Should I go: The Effects of Progress Feedback, Promised Task Duration, and Length of Questionnaire on Completing Web Surveys. International Journal of Public Opinion Research, 23(2), 131-147.

Yu C and Tao Y. (2009). Understanding business-level innovation technology adoption. Technovation, 29, 92-109,

Zhou Y. (2008). Voluntary adopters versus forced adopters: integrating the diffusion of innovation theory and the technology acceptance model to study intraorganization adoption. New Media \& Society, 10(3), 475-496. 